\title{
Chromosome 22q11.2 Deletion Presenting with Immune-Mediated Cytopenias, Macrothrombocytopenia and Platelet Dysfunction
}

\author{
N.A. Akar ${ }^{a} \quad$ A.D. Adekile ${ }^{a, b}$ \\ ${ }^{a}$ Department of Pediatrics, Mubarak Hospital, and ${ }^{b}$ Faculty of Medicine, Kuwait University, Kuwait
}

\section{Key Words}

Chromosome 22q11.2 deletion • Immune cytopenia •

Platelet dysfunction

\begin{abstract}
Objective: To report a case of chromosome 22q11.2 deletion presenting with large platelets, platelet dysfunction, immune-mediated thrombocytopenia and neutropenia, in addition to other features of the disease. Case Presentation and Intervention: The patient presented in the neonatal period with tetralogy of Fallot, subtle dysmorphic features and thrombocytopenia. Fluorescent in situ hybridization analysis confirmed the diagnosis of chromosome 22q11.2 deletion. Further investigations showed immune thrombocytopenia and neutropenia in addition to reduced expression of platelet GPIb and abnormal platelet aggregation studies. CD4:CD8 ratio was reversed. His cardiac abnormality was successfully corrected surgically. He had mild recurrent bacterial infections. Recurrent epistaxis was becoming increasingly more severe, and he had cognitive developmental and speech delay. His serum calcium, phosphorus and parathormone have remained normal. Conclusions: Immune thrombocytopenia can coexist with macrothrombocytopenia and platelet dysfunction in chromosome 22q11.2 deletion and may present with significant bleeding episodes.
\end{abstract}

Copyright $\odot 2007$ S. Karger AG, Basel (c) 2007 S. Karger AG, Basel

1011-7571/07/0164-0318\$23.50/0

Fax +4161306 1234

E-Mail karger@karger.ch

www.karger.com
Accessible online at:

www.karger.com/mpp

\section{Introduction}

Chromosome 22q11.2 deletion syndrome is a common chromosomal disorder with an estimated prevalence of $1: 4,000-6,000$. It encompasses DiGeorge syndrome, velocardiofacial (Shprintzen) syndrome, conotruncal anomaly-face syndrome, Caylor cardiofacial syndrome and the autosomal dominant Opitz BBG syndrome [1]. All these syndromes share a common genetic background, which is a microdeletion of chromosome 22q11.2. It is associated with a wide spectrum of clinical findings without genotype/phenotype correlation even among affected family members [1]. Clinical features include facial dysmorphism, cardiac defects, immune deficiency, endocrine problems, autoimmune problems, learning difficulties and psychiatric disorders $[1,2]$. We describe a patient with Ch22q11.2 deletion, who developed autoimmune thrombocytopenia and neutropenia and also had evidence of macrothrombocytopenia and platelet dysfunction. We are not aware of a previous report of the coexistence of immune thrombocytopenia and platelet dysfunction in the same patient.

\section{Case Report}

J.H. is the 5th child of consanguineous Kuwaiti parents, diagnosed as acyanotic tetralogy of Fallot at the age of 1 month. At 7 months of age he presented with generalized petechiae and a 
platelet count of $9 \times 10^{9} / \mathrm{l}$. He was otherwise well and all other hematological parameters and bone marrow examination were normal. A diagnosis of immune thrombocytopenic purpura was made and he improved spontaneously. He relapsed at 11 months of age and he received systemic steroids to raise his platelet count prior to elective cardiac surgery. The platelet count increased to $164 \times 10^{9} / 1$. The surgery was successful, but he required platelet infusion and blood transfusion because of postoperative bleeding. His cardiac condition was stable afterwards and his platelet count ranged between 120 and $150 \times 10^{9} / 1$ for 3 years after his surgery without steroids or any other treatment.

At the age of 4.5 years it became obvious that he was developmentally delayed especially in speech. Subtle dysmorphic features were now documented - small eyes with narrow palpebral fissures, prominent nose with a dimple at the tip, small posteriorly rotated ears with folded helices and a small mouth with hypoplastic mandible. Fluorescent in situ hybridization analysis confirmed chromosome 22q11.2 deletion. Serum calcium, phosphorus, alkaline phosphatase and parathormone were all normal. There was a persistent marked lymphopenia affecting $\mathrm{T}$ and $\mathrm{NK}$ populations but $\mathrm{B}$ cells were normal. He was negative for antinuclear antibodies and serum immunoglobulins and IgG subclasses were normal. He had several mild infections, mainly upper respiratory with none requiring hospitalization.

At the age of 7.5 years he had neutropenia on a routine complete blood count with a white blood cell count of $3.8 \times 10^{9} / 1$, absolute neutrophil count of $0.5 \times 10^{9} / 1$ and lymphocytes of $2 \times$ $10^{9} / \mathrm{l}, \mathrm{Hb} 117 \mathrm{~g} / \mathrm{l}$ and platelets $48 \times 10^{9} / 1$ with few giant platelets on the blood film. He was asymptomatic and the cell counts improved spontaneously but platelets remained low at $40 \times 10^{9} / 1$. He later developed multiple ecchymotic patches and his platelet count dipped to $11 \times 10^{9} / 1$ and absolute neutrophil count to 0.3 $\times 10^{9} /$ l. He received intravenous immunoglobulins at a dose of $1 \mathrm{~g} / \mathrm{kg}$ for 2 days and his platelets increased to $44 \times 10^{9} / \mathrm{l}$ and the absolute neutrophil count to $0.9 \times 10^{9} / 1$ before discharge from the hospital.

He was evaluated in Great Ormond Street Hospital for Sick Children in London in August 2005. His immunological workup showed slight immune dysregulation with a reversed CD4:CD8 ratio and elevated serum IgA level. Antineutrophil antibodies were positive by both indirect granulocyte chemiluminescence test and indirect granulocyte immunofluorescence test. Antilymphocyte antibodies were negative. Bone marrow examination showed normal cellularity with plentiful megakaryocytes and normal erythroid and myeloid series. Platelet-specific antibodies were positive by direct assay. Platelet aggregation with ristocetin was abnormal and he had mild prolongation of the platelet function assay (in vitro bleeding time). Platelet glycoprotein studies showed reduced expression of GP1b.

The patient is now 9 years old, his cardiac condition is stable and he attends special education class. He has recurrent sinusitis and epistaxis that is controlled with simple measures and tranexamic acid. However, the last two episodes of epistaxis were severe and required platelet transfusion. He still has chronic benign neutropenia that improves spontaneously. $\mathrm{His} \mathrm{Hb}$ is stable between 120 and $130 \mathrm{~g} /$ l; platelets range between 100 and $155 \times$ $10^{9} / 1$ with dips to about $25 \times 10^{9} / 1$ with intercurrent illnesses. Serum calcium, phosphorus and parathormone levels remain normal and he has not had any serious infection.

Immune Cytopenias in Chromosome 22q11.2 Deletion

\section{Discussion}

Patients with the chromosome 22q11.2 deletion are heterogeneous in the frequency and severity of their presenting features $[1,2]$. Cardiac malformations, speech delay and immunodeficiency are the most common characteristics. Immune deficiency has been reported in $40-95 \%$ of cases and the spectrum ranges from profound to nonexistent $[1,2]$. Cell-mediated immune deficiency is more common but disorders of humoral immunity also occur. As a consequence of thymic hypoplasia, patients typically have diminished T-cell numbers, but function is usually preserved [3]. Antibody production is generally normal, although serum IgA may be increased. Another consequence of the immune deficiency is autoimmune disease, which is seen in approximately $9 \%$ of all patients [3]. Diabetes has been described [4], as has autoimmune thyroid disease [5] and juvenile rheumatoid arthritis [6]. Neonatal hypocalcemia is one of the strongest predictors of chromosome 22q11.2 syndrome and reflects the hypoplastic parathyroid glands $[2,7]$.

Hematological problems in the form of autoimmune thrombocytopenia, pancytopenia and Evan's syndrome have been reported [8]. Indeed, it has been estimated that immune thrombocytopenic purpura is seen about 200 times more in patients with 22q.11.2 deletion than in the general population $[4,7,9]$. Macrothrombocytopenia, even after the exclusion of immune thrombocytopenic purpura, has been suggested as a well-defined feature of the wide spectrum of 22q11.2 deletion [10]. Other studies confirmed the presence of increased platelet size $>10 \mathrm{fl}$, with a strong negative correlation between the mean platelet volume and platelet count. Macrothrombocytopenia is probably due to haploinsufficiency of the GPIb gene, which is within the commonly deleted region [10].

The other possibility to consider is that our patient could have Bernard-Soulier syndrome (BSS), which is also characterized by macrothrombocytopenia and platelet dysfunction although the platelet count is usually only moderately reduced (commonly $\left.50-100 \times 10^{9} / 1\right)$. BSS is inherited in an autosomal recessive fashion and the underlying molecular defects are in the Gplb-V-IX complex. BSS has also been reported in association with the 22q11.2 deletion [11, 12]. However, unlike in our patient, recurrent mucosal bleeding, bruises and ecchymosis would commence early in life and be persistent.

Our patient had tetralogy of Fallot, mild dysmorphic features and developmental delay, especially in speech, 
typically seen in this syndrome. His immune deficiency with elevated serum IgA is also consistent. He showed reduced expression of platelet glycoprotein GP1b, thus explaining his platelet dysfunction. This is in coexistence with macrothrombocytopenia and immune neutropenia. This combination is rare and probably contributes to his frequent epistaxis, which is becoming increasingly troublesome and difficult to manage. Otherwise he does not have frequent severe infections and his cognitive development is not too compromised.

\section{Conclusion}

Immune thrombocytopenia can coexist with macrothrombocytopenia and platelet dysfunction in chromosome 22q11.2 deletion and may present with significant bleeding.

\section{Acknowledgments}

We appreciate the efforts of all our colleagues who have been involved in the management of this patient, including cardiologists, cardiothoracic surgeons, hematologists and immunologists.

\section{References}

-1 Ryan AK, Goodship JA, Wilson DI, Philip N, Levy A, Seidel H, Schuffenhauer S, Oechsler H, Belohradsky B, Prieur M, Aurias A, Raymond FL, Clayton-Smith J, Hatchwell E, McKeown C, Beemer FA, Dallapiccola B, Novelli G, Hurst JA, Ignatius J, Green AJ, Winter RM, Brueton L, Brondum-Nielsen K, Scambler PJ: Spectrum of clinical features associated with interstitial chromosome 22q11 deletions. European collaborative study. J Med Genet 1997;34:798-804.

-2 Perez E, Sullivan KE: Chromosome 22q11.2 deletion syndrome (DiGeorge and velocardiofacial syndromes). Curr Opin Pediatr 2002;14:678-683.

3 Jawad AF, McDonald-McGinn DM, Zackai E, Sullivan KE: Immunologic features of chromosome 22q11.2 syndrome (DiGeorge syndrome/velocardiofacial syndrome). J Pediatr 2001;139:715-723.

-4 Elder DA, Kaiser-Rogers K, Aylsworth AS, Calikoglu AS: Type I diabetes mellitus in a patient with chromosome 22q11.2 deletion syndrome. Am J Med Genet 2001;101:17-19.
5 Brown JJ, Datta V, Browning MJ, Swift PG: Grave's disease in DiGeorge syndrome: patient report with a review of endocrine autoimmunity associated with 22q11.2 deletion. J Pediatr Endocrinol Metab 2004;17:15751579.

6 Sullivan K, McDonald-McGinn D, Driscoll D, Reed L, Emanuel BS, Zackai E, Athreya BH, Keenan G: Juvenile rheumatoid arthritis like polyarthritis in chromosome 22q11.2 deletion syndrome (DiGeorge anomaly/velocardiofacial syndrome/conotruncal anomaly face syndrome). Arthritis Rheum 1997; 40:430-436.

7 van den Bosch MA, Wittebol S, van Dijk H, Kramer MH: Hypocalcemic tetany as an early sign of DiGeorge syndrome in an adult woman. Am J Med 2002;112:161-162.

8 Davies JK, Telfer P, Cavenagh JD, Foot N, Neat M: Autoimmune cytopenias in the 22q11.2 deletion syndrome. Clin Lab Haematol 2003;25:195-197.
9 Kawame H, Adachi M, Tachibana K, Kurosawa $\mathrm{K}$, Ito $\mathrm{F}$, Gleason MM, Weinzimer S, Levitt-Katz L, Sullivan K, McDonaldMcGinn DM: Grave's disease in patients with 22q11.2 deletion. J Pediatr 2001;139: 892-895.

10 Kato T, Kosaka K, Kimura M, Imamura S, Yamada O, Iwai K, Ando M, Joh-o K, Ohtake A, Takao A, Momma K, Matsuoka R: Thrombocytopenia in patients with 22q11.2 deletion syndrome and its association with glycoprotein Ib- $\beta$. Genet Med 2003;5:113-119.

- 11 Budarf ML, Konkle BA, Ludlow LB, Michaud D, Li M, Yamashiro DJ, McDonaldMcGinn D, Zackai EH, Driscoll DA: Identification of a patient with Bernard-Soulier syndrome and a deletion in the DiGeorge/ velo-cardio-facial chromosomal region in 22q11.2. Hum Mol Genet 1995;4:763-766.

12 Nakagawa M, Okuno M, Okamoto N, Fujino $\mathrm{H}$, Kato H: Bernard-Soulier syndrome associated with 22q11.2 microdeletion. Am J Med Genet 2001;99:286-288. 